\title{
Interleukin-5 and interleukin-10 are major cytokines in cerebrospinal fluid from patients with active neurocysticercosis
}

V. Rodrigues Jr. ${ }^{1}$, F.A. de-M ello ${ }^{1}$, E.P. Magalhães ${ }^{1}$, S.B.F. Ribeiro ${ }^{2}$ and J.O. Marquez ${ }^{2}$

\author{
'Laboratório de Imunologia and ${ }^{2} D$ isciplina de Neurologia, \\ Faculdade de Medicina do Triângulo Mineiro, Uberaba, MG, Brasil
}

\section{Correspondence}

V. Rodrigues Jr.

Laboratório de Imunologia

Faculdade de Medicina do

Triângulo Mineiro

Rua Frei Paulino, 30

38025-180 U beraba, M G

Brasil

Fax: + 55-34-312-6640

E-mail: vrodrigues@ mednet.com.br

Research supported by FAPEMIG and CNPq. F.A. de-M ello and

E.P. M agalhães were recipients of

CNPq fellowships (PIBIC program)

Received September 9, 1999

Accepted June 12, 2000

\section{Abstract}

Neurocysticercosis (NCC) is a common neurological disorder especially in developing countries, caused by infection of the brain with encysted larvae of the tapeworm Taenia solium. Seizures are a common finding associated with this disease. The objective of the present study was to evaluate the correlation between the levels of various cytokines present in the cerebrospinal fluid (CSF) of patients with NCC and the severity of the disease. The levels of the cytokines IL-1B, TNF- $\alpha$, IL-5, IL-10 and IFN- $\gamma$ were determined in the CSF of 22 patients with active NCC, 13 patients with inactive NCC and 15 control subjects. CSF from patients with active NCC presented significantly higher IL-5 levels compared to control subjects. IL-5 and IL-10 levels in CSF from NCC patients with inflammatory CSF were significantly higher than those detected in non-inflammatory CSF. These results show a predominant $\mathrm{Th} 2$ lymphocyte activation in human NCC and also indicate the possible use of cytokines in the CSF as a marker for the differential diagnosis between inactive disease and the active form of NCC.

\section{Introduction}

Neurocysticercosis (NCC) is a common neurological disorder in several developed and developing countries. It is endemic in Latin America, Asia and Central and South Africa and is relatively frequent in Portugal, Spain and Eastern European countries (1-3). In other developed countries NCC can be frequent among immigrants. The disease is caused by the encysted larvae of the tape-
Key words

- Cysticercosis

- Cytokines

- Cerebrospinal fluid worm Taenia solium lodged in the central nervous system (CNS). In the same communities, teniasis is a public health problem with a frequency of family antecedents reaching $34.2 \%$ in some regions (4).

NCC may be asymptomatic or may cause a variety of clinical manifestations depending on the number, location and stage of development of the cysticercus-associated lesions. Epileptic seizures, hydrocephaly and intracranial hypertension, in this order, are 
the most frequent clinical features. This pleomorphic disease is a result of the presence of the parasite itself (cysticerci), the inflammatory process that surrounds the larvae, and the residual fibrosis and calcification $(5,6)$.

The cysticercus contains a large number of antigens that can elicit a host immuneinflammatory reaction. The inflammatory cellular infiltrate, if present, may be discrete with the presence of lymphocytes and eosinophils in the vesicular stage, or may be a more intense lymphocyte infiltrate with giant multinuclear foamy macrophages in the necrotic stage, with parasites in different stages of desintegration (7).

Most of the previous studies involving cerebrospinal fluid (CSF) were limited to an analysis of the presence of specific antibodies and nonspecific mediators of the inflammatory reaction such as parasite-specific antibodies, increased protein levels and eosinophilia (8). Eosinophilia provides indirect evidence for the active form of NCC. Recently, several reports on cysticercosis involving studies of the cellular infiltrate in humans and in animal models have indicated that a Th1 immune response predominates over a Th2 response $(9,10)$, while studies of the CSF have revealed a predominant Th2 response $(11,12)$.

Cytokines are pleotropic hormones that regulate many aspects of the immune response and of inflammatory reactions. Interleukin-5 (IL-5) is produced mainly by Th2 lymphocytes and plays a role in eosinophil maturation, migration and activation and also induces immunoglobulin A switch in B lymphocytes (13). Interleukin-10 is produced by Th2 lymphocytes, B cells, and macrophages and has strong anti-inflammatory properties (14). Interferon- $\gamma$ (IFN- $\gamma$ ) is produced by Th1 lymphocytes and natural killer (NK) cells and is involved in macrophage activation and in immunoglobulin class switch (15). Other cytokines such as IL-1ß and tumor necrosis factor alpha (TNF- $\alpha$ ) are produced mainly by macrophages and by glial cells in the CNS, and are involved in the acute phase of inflammatory reactions.

In the present study, we determined the presence of IL-5, IL-10, IFN- $\gamma$, TNF- $\alpha$ and IL- $1 \beta$ in CSF from patients with active and inactive NCC and compared their levels with those found in the CSF of unaffected controls. The results indicate that high levels of IL-5 are significantly associated with active NCC and that IL-10 reaches higher levels in inflammatory CSF.

\section{Patients and Methods}

\section{Patients}

CSF samples collected from 22 patients with active NCC, 13 with inactive NCC and 15 controls (patients with chronic headache, normal topography and standard parameters of CSF analysis within normal values) were analyzed. All patients and controls were submitted to neurological investigation including clinical examination, brain tomography and standard CSF analysis. CSF analyses consisted of serological tests for anti-cysticercus and anti-treponema antibodies, protein concentration, sodium, potassium and chloride measurements, and standard blood cell counts. Patients with active and inactive NCC were classified on the basis of a brain tomography scan (16). All of them exhibited anti-cysticercus antibodies in CSF and were negative for anti-treponema antibodies. This study was approved by the Ethics Committee of the Faculdade de Medicina do Triângulo Mineiro.

\section{Cytokine titration}

For cytokine titration, microplates (Nunk, Roskilde, Denmark) were sensitized with anti-IL-1ß mAb (Genzyme, Cambridge, MA, USA), anti-TNF- $\alpha$ (Genzyme), anti-IL-5 mAb (Pharmingen, San Diego, CA, USA), anti-IL-10 mAb (Pharmingen), or anti-IFN- $\gamma$ mAb (Mabtech, Nacka, Sweden) overnight. 
Nonspecific binding was prevented by incubating the plates with 3\% BSA (Sigma Chemical Co., St. Louis, MO, USA) in PBS. Plates were incubated overnight with $100 \mu 1$ of $1: 2$ dilution of CFS in PBS, 2\% BSA and standard cytokines (Pharmingen and R\&D, Minneapolis, MN, USA). Plates were then washed 4 times with PBS and $0.05 \%$ Tween and incubated with rabbit anti-IL- $1 \beta$ antibody (Genzyme), rabbit anti-TNF- $\alpha$ antibody (Genzyme), biotinylated anti-IL-5 $\mathrm{mAb}$ (Pharmingen), biotinylated anti-IL-10 $\mathrm{mAb}$ (Pharmingen) or biotinylated anti-IFN$\gamma$ mAb (Mabtec) for $4 \mathrm{~h}$. Plates were then washed and incubated for $2 \mathrm{~h}$ with alkaline phosphatase-conjugated goat anti-rabbit IgG (Immunotech, Marseille, France) or alkaline phosphatase conjugated to streptavidin. Finally, plates were washed 4 times and enzymatic activity was developed by incubating the plates with p-nitrophenyl phosphate (Sigma). Absorbance was read at $405 \mathrm{~nm}$ in a microplate reader apparatus (Biorad, Hercules, CA, USA). The sensitivity of the tests was $20 \mathrm{pg} / \mathrm{ml}$.

\section{Results}

Patients with NCC were classified according to a computer tomography scan and the presence of anti-cysticercus antibodies (14). As shown in Figure 1, CSF from patients with inactive NCC did not present relevant alterations in cellularity or protein concentration. Nevertheless, 8 patients with active NCC presented elevation of cells and proteins in CSF, with eosinophils ranging from 4 to $9 \%$.

Levels of IL-1ß, TNF- $\alpha$, IL-5, IL-10 and IFN- $\gamma$ were measured in CSF by ELISA. CSF from the majority of control patients did not present measurable levels of the tested cytokines. The levels of TNF- $\alpha$ and IFN- $\gamma$ were below the limit of detection in the study group. CSF from patients with active NCC showed an elevation of IL-1, IL-5, and IL-10 levels. IL-5 levels were significantly higher
( $t$-test) than those found in the CSF from patients with inactive NCC and from control subjects (Figure 2). These findings were particularly clear when patients with alterations in terms of both cellular and biochemical criteria were compared with the other group. In the CSF from patients with active NCC with protein concentration above $50 \mathrm{mg} \%$ and more than 20 cells $/ \mathrm{ml}$, IL-5 levels ranged from 57 to $792 \mathrm{pg} / \mathrm{ml}$ and the levels of IL-10 levels ranged from 38 to $398 \mathrm{pg} / \mathrm{ml}$. In contrast, the levels of IL-5 and IL-10 were significantly lower in CSF from patients with active NCC with a non-inflammatory reaction (Figure 3).

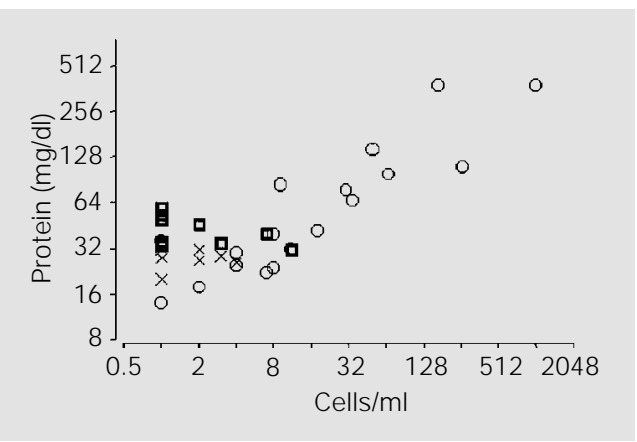

Figure 1 - Protein concentration and cell counts in CSF from patients with active (circles, $\mathrm{N}=22$ ) and inactive (squares, $\mathrm{N}=13) \mathrm{NCC}$ and from control subjects $(X, N=15)$.

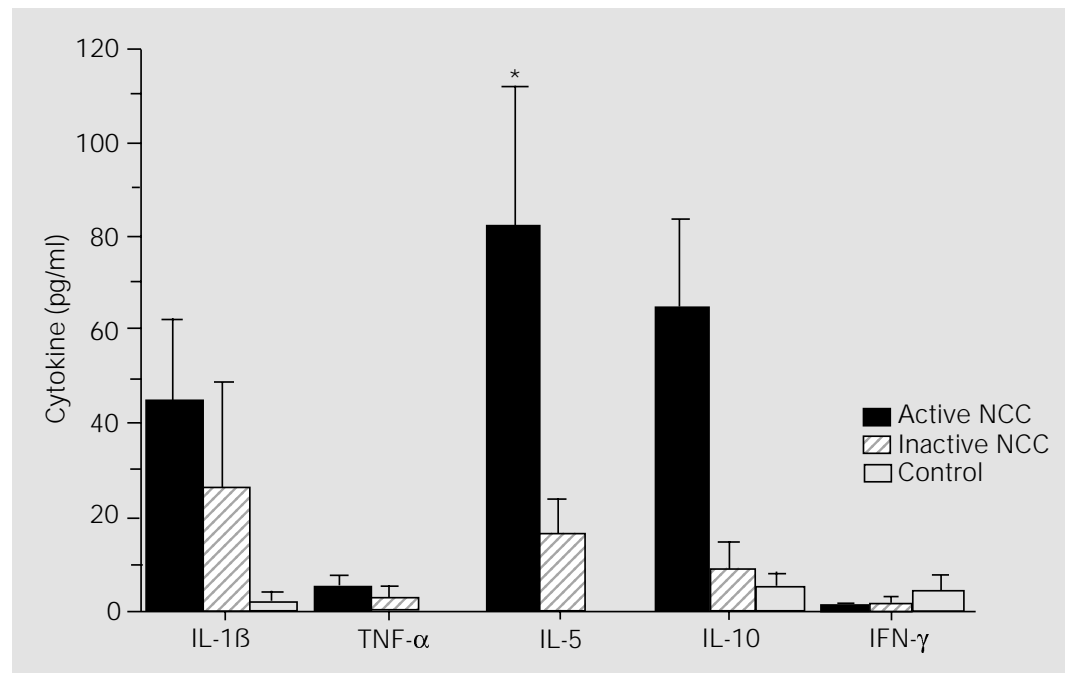

Figure 2 - Cytokine levels in CSF from patients with active (filled bars, $\mathrm{N}=22$ ) and inactive (striped bars, $\mathrm{N}=13$ ) NCC and from control subjects (open bars, $\mathrm{N}=15$ ). The bar represents the mean and the vertical lines the standard error of the mean. Statistical analysis was performed on log-transformed cytokine levels. $* \mathrm{P}<0.05$ compared to control subjects (Student t-test). 


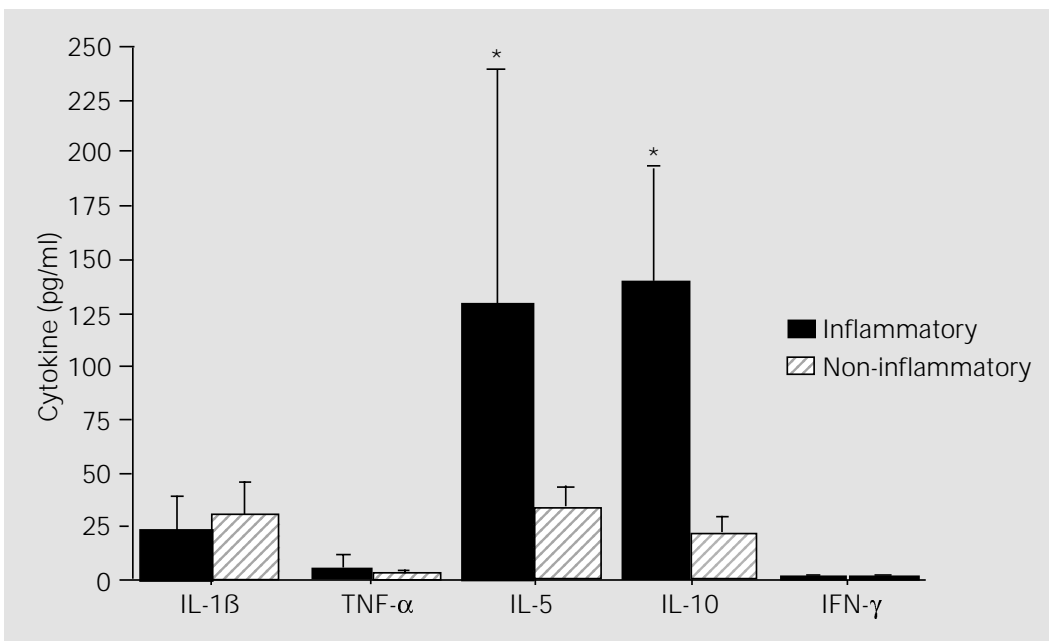

Figure 3 - Cytokine levels in CSF from 8 patients with active NCC with inflammatory CSF (filled bars) and from 14 NCC patients with non-inflammatory (striped bars) CSF based on protein concentrations and cell counts. Statistical analysis was performed on log-transformed cytokine levels. $* \mathrm{P}<0.05$ compared to NCC patients with non-inflammatory CSF (Student t-test). nuclear cells and eosinophils (7). These cyst antigens stimulate the production of antibodies which are inefficient in killing mature metacestodes. However, the anti-cysticercus antibodies can be detected in CSF of patients with active and inactive NCC and are the basis for the immune diagnosis of this disease. The inflammatory reaction of NCC was demonstrated in CSF (19) and confirmed by some studies on experimental models and on human tissues. These studies showed an immune response predominantly consisting of Th1 lymphocytes $(9,10)$ and the later development of a Th2 response associated with parasite destruction (11).

In the present study, we observed that CSF from patients with NCC contains elevated concentrations of IL-1ß, IL-5, and IL10. The levels of these cytokines in the CSF from the majority of uninfected controls was below ELISA sensitivity. However, statistical analysis demonstrated that IL-5 levels were significantly higher in patients with active NCC than in patients with inactive $\mathrm{NCC}$ and in control subjects. Moreover, IL10 and IL-5 levels were higher in active NCC patient with elevated concentrations of proteins and increased cellularity.

Our results are significant because they can help us to understand some of the cellular alterations present in the CSF of NCC patients, i.e., a marked eosinophilia. This alteration may be the result of the intense production of IL-5 during the immune response to the cysticercal antigens, because one of the main functions of IL-5 is to induce and activate eosinophils to mediate an antibody-dependent helminthotoxic effect (20). We suggest that the eosinophilia present in the CSF of patients with active NCC is, at least in part, mediated by the IL- 5 produced by the host in response to the infectious process. Similarly, the presence of IL-10 and the absence of IFN- $\gamma$ in CSF from patients with NCC confirm a Th2 response elicited by helminthic infection. Moreover, IL-10, as an anti-inflammatory cytokine, may be in- 
volved in the control of inflammatory reactions in patients with elevated cell concentration in CSF.

Finally, our results show a predominant activation of Th2 lymphocytes in human NCC, with the presence of increased levels of IL-1ß, IL-5, and IL-10 in the absence of IFN- $\gamma$ and TNF- $\alpha$. These results show that the determination of cytokines in CSF may be an important asset by providing an addi- tional parameter for the differential diagnosis between inactive NCC and active disease.

\section{Acknowledgments}

We would like to thank Dr. Antonio Campos-Neto for a critical review of the manuscript.

\section{References}

1. Ahuja GK, Roy S, Karla G \& Vermin V (1978). Cerebral cysticercosis. J ournal of the Neurological Sciences, 35: 365-374.

2. Del Bruto OH \& Sotelo J (1988). Neurocysticercosis: an update. Review of Infectious Diseases, 10: 1075-1087.

3. White J r AC (1997). Cysticercosis: a major cause of neurological disease worldwide. Clinical Infectious Diseases, 24: 1015.

4. Silva-Vergara $M L$, Prata $A$, Netto HV, Vieira C de O, Castro J H, Micheletti LG, Otano AS \& Franquini J unior J (1998). Risk factors associated with taeniasis-cysticercosis in Lagamar, Minas Gerais State, Brazil. Revista da Sociedade Brasileira de Medicina Tropical, 31: 65-71.

5. Monteiro L, Coelho T \& Stocker A (1992). Neurocysticercosis - A review of 231 cases. Infection, 20: 61-65.

6. Rosenfeld EA, Byrd SE \& Shulman ST (1996). Neurocysticercosis among children in Chicago. Clinical Infectious Diseases, 23: 262-268.

7. Pittella J EH (1997). Neurocysticercosis. Brain Pathology, 7: 681-693.

8. Miller BL, Staugaitis SM, Tourtellotte WW, Shapshak P, Goldberg M, Heiner D \& Weil M (1985). Intra-blood-brain barrier IgG synthesis in cerebral cysticercosis. Archives of Neurology, 42: 782-784.

9. Restrepo BI, Llaguno P, Sandoval MA,
Enciso J A \& Teale J M (1998). Analysis of immune lesions in neurocysticercosis patients: central nervous system response to helminth appears Th1-like instead of Th2. J ournal of Neuroimmunology, 89: 6472.

10. Cardona, $A E$, Restrepo $B I$, J aramillo J M \& Teale J M (1999). Development of an animal model for neurocysticercosis: Immune response in the central nervous system is characterized by a predominance of $\gamma \delta$ T cells. J ournal of Immunology, 162: 995-1002.

11. Robinson $P, A$ tmar RL, Lewis DE \& White J r AC (1997). Granuloma cytokines in murine cysticercosis. Infection and Immunity, 65: 2925-2931.

12. Evans CA, Garcia HH, Hartnell A, Gilman RH, J ose PJ, Martinez $M$, Remick DG, Williams TJ \& Friedland JS (1998). Elevated concentrations of eotaxin and interleukin-5 in human neurocysticercosis. Infection and Immunity, 66: 4522-4525.

13. Takatsu K, Takaki S \& Hitoshi Y (1994). Interleukin-5 and its receptor system: implications in the immune system and inflammation. Advances in Immunology, 57: 145-190.

14. Moore KW, O'Garra A, de Vaal Malefyt R, Vieira P \& Mosmann TR (1993). Interleukin-10. Annual Review of Immunology, 11: 165-190.
15. Finkelman FD, Holmes J, Katona IM, Urban J J JF, Beckmann MP, Park LS, Schooley KA, Coffman RL, Mosmann TR $\&$ Paul WE (1990). Lymphokine control of in vivo immunoglobulin isotype selection. Annual Review of Immunology, 8: 303333.

16. Sotelo J MD, Guerrero V \& Rubio F (1985). Neurocysticercosis: a new classification based on active and inactive forms: A study of 753 cases. Archives of Internal Medicine, 145: 442-445.

17. Ridaura Sanz C (1987). Host response in childhood neurocysticercosis. Childs Nervous System, 3: 206-207.

18. Gutierrez Y (1990). Cysticercosis, coenurosis, and sparganosis. In: Gutierrez $Y$ (Editor). Diagnostic Pathology of Parasitic Infection with Clinical Correlation. Lea \& Febiger, Philadelphia, 432-459.

19. Ostrosky-Zeichner L, Mendonza EG, Rios C \& Sotelo J (1996). Humoral and cellular immune response within the subarachnoid space of patients with neurocysticercosis. Archives of Medical Research, 27: 513-517.

20. Butterworth $A E$, Strurrock RF, Houba $V$, Mohmoud AAF, Sher A \& Rees PH (1975). Eosinophils as mediators of antibody-dependent damage to schistosomula in vitro. Nature, 26: 727-729. 